\title{
O Processo de Territorialização do Agronegócio Global na Microrregião Geográfica de Rondonópolis - MT, a partir da década de 1970
}

\author{
The Process of Territorialization of Global Agribusiness in the Geographic Microregion of \\ Rondonópolis - MT, from the 1970
}

El Proceso de Territorialización del Agronegocio Global en la Microrregión Geográfica de Rondonópolis - MT, a partir de la década de 1970

\author{
Roberto Souza Santos ${ }^{1}$
}

\begin{abstract}
RESUMO: O artigo levanta uma discussão teórica e empírica sobre as contribuições do processo de modernização na reorganização do espaço agrário e no fortalecimento político e econômico de um grupo de atores sociais vinculados ao agronegócio na Microrregião de Rondonópolis - MT, a partir da década de 1970, com a introdução do progresso técnico-científico no espaço agrário dentro do modelo de produção capitalista. Observa e estuda a influência da introdução do progresso técnicocientífico na modernização da economia e do espaço agrário, bem como o papel que este progresso desempenhou no fortalecimento político e econômico do setor ligado ao agronegócio. O texto aborda as estratégias dos agentes do agronegócio no processo de produção tanto a montante quanto a jusante no setor agrícola. Observa as ações e estratégias de territorialização das empresas globais do agronegócio e sua influência na reorganização e produção do espaço regional e a subordinação dos agricultores à sua arena geopolítica comercial. Adotou-se o método qualitativo e a elaboração do artigo baseou-se em uma revisão bibliográfica e em uma pesquisa empírica. Após o levantamento bibliográfico, procedeu-se a compilação, organização das ideias e interpretação dos dados e informações teóricas e empíricas disponíveis na literatura adotada e nas pesquisas de campo.
\end{abstract}

PALAVRAS-CHAVE: Modernização do espaço agrário. Microrregião de Rondonópolis. Empresas globais do agronegócio.

ABSTRACT: The article raises a theoretical and empirical discussion about the contributions of the modernization process to the reorganization of the agrarian space and the political and economic strengthening of a group of social actors linked to agribusiness in the Microregion of Rondonópolis MT, from the 1970s onwards, the introduction of technical-scientific progress in the agrarian space within the model of capitalist production. To observe and study the influence of the introduction of technical and scientific progress in the modernization of the economy and the agrarian space, as well as the role that this progress has played in the political and economic strengthening of the sector related to agribusiness. The text deals with the strategies of agribusiness agents in the production process both upstream and downstream in the agricultural sector and observe the actions and strategies of territorialization of global agribusiness companies and their influence in the

\footnotetext{
${ }^{1}$ Universidade Federal de Tocantins. Rua 03, Quadra 17, Lote 11, s/n. Setor Jardim dos Ipês | $77500-000$ | Porto Nacional/TO. robertosantos@uft.edu.br.
} 
reorganization and production of the regional space and the subordination of the farmers to their commercial geopolitical arena. The qualitative method was adopted, and the article was based on a bibliographical review and empirical research. After the bibliographical survey, we compiled, organized the ideas and interpreted the data and theoretical and empirical information available in the literature and the field research.

KEYWORDS: Modernization of agrarian space. Rondonópolis Microregion. Global agribusiness companies.

RESUMEN: El artículo plantea una discusión teórica y empírica sobre las contribuciones del proceso de modernización en la reorganización del espacio agrario y en el fortalecimiento político y económico de un grupo de actores sociales vinculados al agronegocio en la Microrregión de Rondonópolis - MT, a partir de la década de 1970, la introducción del progreso técnico-científico en el espacio agrario dentro del modelo de producción capitalista. Observar y estudiar la influencia de la introducción del progreso técnico-científico en la modernización de la economía y del espacio agrario, así como el papel que este progreso desempeñó en el fortalecimiento político y económico del sector vinculado al agronegocio. El texto aborda sobre las estrategias de los agentes del agronegocio en el proceso de producción tanto a nivel, como aguas abajo en el sector agrícola. Observar las acciones y estrategias de territorialización de las empresas globales del agronegocio y su influencia en la reorganización y producción del espacio regional y la subordinación de los agricultores a su arena geopolítica comercial. Se adoptó el método cualitativo y la elaboración del artículo se basó en una revisión bibliográfica y en una investigación empírica. Después del levantamiento bibliográfico, se procedió a la compilación, organización de las ideas e interpretación de los datos e informaciones teóricas y empíricas disponibles en la literatura adoptada y en las encuestas de campo.

PALABRAS-CLAVE: Modernización del espacio agrario. Microrregión de Rondonópolis. Empresas globales del agronegocio.

\section{INTRODUÇÃO}

O artigo procura compreender a contribuição do processo de modernização na reorganização do espaço agrário e no fortalecimento político e econômico de um grupo de atores sociais vinculados ao agronegócio na Microrregião de Rondonópolis - MT. Tem também o objetivo de analisar e verificar o processo de modernização na economia agropecuária da região a partir da década de 1970, com a introdução do progresso técnicocientífico no espaço agrário dentro do modelo de produção capitalista.

Nas regiões onde o agronegócio atua o processo de modernização na reorganização espacial é um tema atual, portanto deve ser analisado teórica e empiricamente pelo viés acadêmico e científico. A temática pesquisada e analisada é importante e de interesse para o debate teórico-metodológico na academia no que diz respeito ao processo de modernização e territorialização do agronegócio. Esse é um tema que deve ser avaliado e questionado e colocado ao conhecimento da opinião pública pelos meios de publicação dos trabalhos científicos como nas revistas científicas. Este artigo é relevante não só pelo fato 
da abordagem científica dos fenômenos observados teórica e empiricamente, mas pela grande responsabilidade e compromisso de diagnosticar e avaliar a temática em pauta.

Os procedimentos teórico-metodológicos foram organizados e estruturados a partir de uma análise teórico-crítica sobre o processo de territorialização do agronegócio global na Microrregião de Rondonópolis - MT dentro do modelo de produção capitalista. A discussão teórico-metodológica procede de duas formas: um debate teórico a partir da interpretação do referencial bibliográfico utilizado e trabalhado e uma reflexão a partir das experiências e pesquisas acumuladas durante as pesquisas do doutorado entre 2001 a 2006. O texto ainda é resultado de experiências e pesquisas bibliográficas e empíricas durante o estágio de pósdoutorado em 2013 no Instituto de Estudos Socioambientais da Universidade Federal de Goiás (IESA/UFG).

O recorte analítico utilizado no desenvolvimento da reflexão compreende o processo de territorialização do agronegócio global na Microrregião de Rondonópolis, que se estabeleceu a partir da modernização e reorganização do espaço agrário, por intermédio da introdução do progresso técnico e científico.

O recorte espacial adotado para análise e pesquisa é da Microrregião Geográfica de Rondonópolis - a análise parte do pressuposto de que os fenômenos objetivados não se restringem à fronteira física da microrregião, principalmente quando se trata de verificação e análise dos fenômenos geográficos pela sua complexidade. Em nossa análise, a escala é vista como uma estratégia de apreensão da realidade, que define o campo empírico da pesquisa, considerando que são os fenômenos que dão o sentido ao recorte espacial objetivado e também à categoria de análise. A análise geográfica dos fenômenos exige que a apreensão do espaço aconteça na escala em que ele é percebido, levando em conta que um espaço ou uma região possui uma dimensão territorial e uma dimensão social que interagem e configuram uma escala particular do espaço, como afirma Castro (1995). A Microrregião Geográfica de Rondonópolis está localizada na mesorregião sudeste matogrossense, conforme ilustra a Figura 1, a seguir.

No recorte temporal, a intenção é levantar uma discussão teórica sobre o processo de modernização do espaço agrário regional de Rondonópolis a partir de 1970. Entretanto, é necessário salientar que a evolução do processo de formação do espaço agrário matogrossense deve ser entendida na sua totalidade, uma vez que um momento da realidade pode representar uma visão fragmentada do objeto. A formação do espaço agrário é um processo. Em Mato Grosso, este processo começa com a presença geopolítica da Coroa portuguesa no controle militar da região. No século $X X$ a concessão de terras na colonização oficial e a doação de glebas no interior do estado contribuíram para a eminência de um grupo de atores sociais capitalistas de cunho agrário. No final do século XX e início 
O Processo de Territorialização do Agronegócio Global na Microrregião Geográfica de...

deste, chegaram à região grandes empresas do agronegócio e agroindústria que condicionaram o uso do progresso técnico-científico e sua racionalidade na economia agropecuária. Com isso, a Microrregião de Rondonópolis adquiriu um desenvolvimento econômico substancial.

Figura 1 - Divisão político-administrativa da Mesorregião Sudeste Mato-grossense

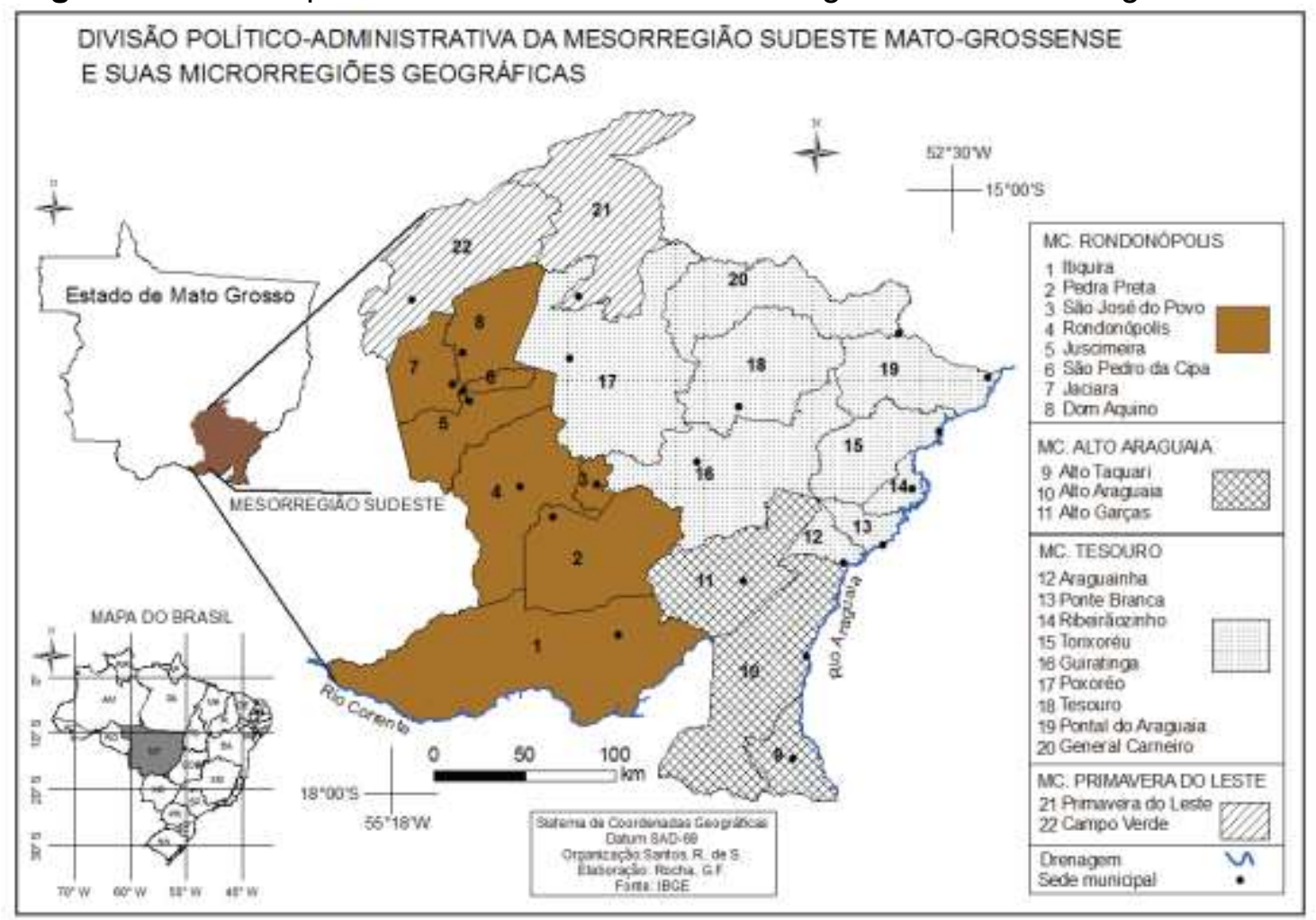

Fonte: Santos, 2016.

O texto está estruturado em dois tópicos. O primeiro procura debater as ações e o processo de territorialização do agronegócio na Microrregião Geográfica de RondonópolisMT. Segundo Mendonça (2013), o agronegócio é um marco conceitual que delimita os sistemas integrados de produção de alimentos, fibras e biomassa, operando desde o melhoramento genético até o produto final, no qual todos os agentes que se propõem a produzir matérias-primas agropecuárias devem fatalmente se inserir, dos camponeses até as multinacionais. O agronegócio global é representado pelas empresas transnacionais que atuam no mundo econômico do agribusiness. Dentre as grandes corporações globais estão as empresas do agronegócio que atuam em vários segmentos produtivos em cadeia para ampliar o exercício de sua territorialidade. Estes segmentos são integrados nas cadeias de grãos-farelo-ração e carnes do agronegócio. A cadeia produtiva se integra também por um conjunto de infraestrutura e institucional com os órgãos estatais e pelas redes técnicas territoriais. Atualmente, as grandes corporações transnacionais procuram novas formas de 
concorrência e coordenação política, fusão e integração de diversas empresas para construir o processo de territorialização no mercado global.

O segundo tópico faz uma análise sobre as ações das empresas globais do agronegócio a montante e a jusante do processo produtivo agropecuário na região de Rondonópolis. Dentro deste complexo, as empresas globais do agronegócio podem atuar nas duas pontas do processo produtivo - a montante e a jusante. A possibilidade de agir e movimentar suas ações nas duas pontas do processo produtivo coloca as empresas globais do agronegócio em um patamar privilegiado para monopolizar o comércio local, nacional e internacional.

\section{PROBLEMATIZANDO CONCEITOS TEÓRICOS SOBRE O TEMA TRABALHADO}

O conceito de espaço agrário discutido no presente artigo é interpretado como uma estrutura totalizante do processo de modernização, em condições de materialização e espacialização contraditória. O espaço agrário se organiza a partir da luta de classes sociais e dos conflitos de interesse. É como escreve Moreira (1991), o espaço agrário segue neste viés de transformação e de reprodução desigual, que imprime novas formas de manutenção das relações sociais, ora associadas, ora contraditórias. O espaço agrário se tornou extremamente complexo com o avanço do capitalismo, quebrando ou reformulando antigas estruturas sociais de produção e criando outras.

O processo de modernização se constrói por meio das redes técnicas como as dos transportes (rodovia e ferrovia) e de energia - são vetores que possibilitam a espacialização dos processos modernos a partir do movimento de circulação e fluxo - e também por meio das redes financeira e de comunicação, que se apresentam na atualidade como de necessidade extrema. O processo de modernização, aqui entendido, refere-se ao capitalismo em ação por meio de suas classes hegemônicas - é o seu processo de expansão e/ou territorialização pelos lugares. Se, por um lado, a modernização carrega uma força que promove a homogeneização dos lugares, por outro acaba por diferenciá-los ainda mais.

Para Castilho (2014), a modernização deve ser entendida como processo territorial articulado dialeticamente por sistemas político-ideológicos e técnico-produtivos que trazem como resultado a conformação de modernizações. A dimensão espacial é um ponto chave para a interpretação da modernização. Isso porque a espacialização é uma condição basilar de sua expansão, sendo o território o lócus das articulações políticas. No Brasil a modernização foi imposta de maneira vertical e autoritária - e continua sendo reproduzida dessa maneira a partir de demandas internacionais e, sobretudo, de articulações de grandes 
O Processo de Territorialização do Agronegócio Global na Microrregião Geográfica de...

corporações, de atores locais e de ações em diferentes escalas. Para Santos (2008), a modernização de um espaço consiste em unir-se econômica, política e socialmente ao mundo moderno. O processo de modernização é um dos principais condicionantes para o estabelecimento do processo de territorialização no capitalismo global: ambos contraditórios entre si, e que constroem um espaço de conflitos de interesse - socialmente desigual.

Este modelo de modernização do espaço agrário leva a outro processo, que é o de territorialização dos agentes econômicos nas diversas escalas espaciais. A expressão territorialização se refere à dinâmica econômica do espaço e do desenvolvimento regional e local de forma contraditória. A noção de territorialização do capital vai além da perspectiva econômica. Territorialização significa apropriação dos recursos naturais, domínio cultural, ideológico, político e econômico por parte do capital no espaço para ampliar a sua geopolítica territorial em uma lógica contraditória. A expressão territorialização indica processo, ação ou a história do desenvolvimento e a luta pelo poder comercial, econômico e político dos atores sociais na arena territorial. É uma ação do ator social no tempo e no espaço em constantes mudanças, isto é, "[...] no capitalismo, os processos materiais de produção social estão em constante mudança, portanto, as categorias tempo e espaço também" (ABRÃO, 2012, p. 45). Territorialização dos atores hegemônicos significa ter o controle e domínio comercial e político do seu mercado na arena global, nacional, regional e local.

O conceito de circuitos espaciais de produção é importante para compreender o processo de modernização e reorganização espacial e o complexo agroindustrial na região de Rondonópolis. Santos e Silveira (2001) trabalham com a noção de circuitos espaciais de produção para compreender o movimento e a circulação de bens e produtos, isto é, os fluxos. Para os referidos autores, os circuitos espaciais de produção "[...] são definidos pela circulação de bens e produtos e, por isso, oferecem uma visão dinâmica, apontando a maneira como os fluxos perpassam o território". (p. 143). Circuitos espaciais de produção se apresentam de forma diferenciada por parte das empresas, das instituições, dos indivíduos e permitem compreender a hierarquia dos lugares desde a escala regional até a escala mundial.

Segundo Santos e Silveira (2001, p. 143), atualmente, "[...] há uma crescente segmentação territorial das etapas do trabalho, intensificando-se as trocas e relações entre as regiões". As trocas não são obrigatoriamente entre áreas contíguas. Uma área de agricultura moderna pode não ter relações com a cidade mais próxima, todavia pode ter relações com lugares distantes ou mesmo com o estrangeiro. A região de Rondonópolis se encaixa nesse perfil, que mantem relações com o mercado internacional no mundo do agronegócio. Na região, superpõem-se diversos circuitos da produção como de fertilizantes, 
sementes melhoradas e produção de grãos. Mas, atualmente, esse movimento não só é comandado por fluxos materiais, como também por imateriais, como a informação.

\section{ESTRATÉGIAS TERRITORIAIS DAS EMPRESAS DO AGRONEGÓCIO NA MICRORREGIÃO DE RONDONÓPOLIS}

A expansão do capitalismo no campo a partir de meados da década de 1980 inseriu a Microrregião de Rondonópolis na cadeia produtiva agroindustrial nacional e internacional, o que permitiu a territorialização dos sujeitos econômicos na região. A territorialização do grande capital na região começou com a implantação das primeiras empresas na metade da década de 1970, com a abertura da Sementes Bonjour em 1973, que atua na pesquisa de sementes de pastagens. Já em 1975 se instalam, na região, a Agropecuária Maggi, a Agropecuária Guarita e a Sementes Mônica, que atuam na produção de soja. Com isso, marcou-se o início da territorialização do capital no espaço agrário regional, por meio da ampliação da estrutura de armazenagem da produção, da estruturação de uma rede de assistência técnica e de pesquisa, do sistema de financiamento e de crédito e dos projetos agropecuários, - estes foram e são os verdadeiros condicionamentos para o processo de territorialização do capital na região.

A década de 1970 caracterizou-se pela expansão e especialização da produção agrícola regional, e o período posterior, a partir de 1980, foi marcado pela expansão do capital monopolista agroindustrial, ou seja, pela implantação das empresas globais. Em meados da década de 1980 instalaram-se na região de Rondonópolis empresas, de expressão nacional e internacional, ligadas ao processamento de produtos agrícolas e alimentos, como Sadia, Sanbra, Ceval e Anderson Clayton, conforme relata Santos (2002). A instalação destas empresas caracterizou o primeiro grande complexo agroindustrial, com esmagamento de soja e refino de óleo de soja, assumindo a função de gestão do território do agronegócio na região. As indústrias assumiram o financiamento da produção agrícola nesta fase e estabeleceram uma nova dinâmica socioeconômica no sistema da produção agrícola. Monteiro (2004) salienta que a reestruturação espacial induzida em Rondonópolis, após a segunda metade dos anos 1970, possui uma dinâmica que está diretamente relacionada ao dinamismo da produção do campo.

No modo de produção capitalista, o espaço sempre terá que se reestruturar para se adequar às novas situações da busca da mais-valia. Na Microrregião de Rondonópolis, para as empresas do agronegócio continuarem buscando a mais-valia em maior escala, foi necessário adaptar a economia local e regional às novas exigências do capital internacional. Houve uma reestruturação da funcionalidade do espaço, pela qual, muitas das áreas 
agrícolas tradicionais e, especialmente, as áreas do cerrado passaram a ser o novo palco das práticas econômicas ligadas ao agronegócio. Nesse processo, há todo um segmento social que vai se organizando e se fortalecendo, econômica e politicamente, tendo, inclusive, conseguido orquestrar os seus interesses econômicos e políticos com o aparelho estatal. Isto se verifica num sistema que integra um conjunto de inúmeras relações espaciais da sociedade, as quais englobam esferas como a política, a técnica e a economia, e cujo objetivo maior é obter o pleno êxito da acumulação capitalista, tendo à frente desse processo os agentes hegemônicos, como afirma Silva (2005).

O projeto político-econômico neoliberal impôs regulamentos mais flexíveis ao processo de globalização do capital financeiro. Para estar presente no mercado global o capital necessita de uma maior mobilidade espacial. Com as novas tecnologias o capital é deslocado de um lugar a outro em tempo real. Entretanto, as inovações técnicas não são incorporadas ao mesmo tempo por toda a sociedade: elas são seletivas. E, ao serem selecionadas pelos sujeitos econômicos, ampliam-se as desigualdades regionais e ampliase também o processo de polarização econômica e regional. Partindo deste raciocínio, podemos afirmar que a Microrregião de Rondonópolis foi um espaço que as empresas do agronegócio global adotaram (selecionaram) para a busca da mais-valia. Nesse processo, o espaço local e regional não é regulado apenas pelo Estado e sim, também, pelas grandes corporações. Evidenciam-se as disputas pelo poder entre os sujeitos econômicos, isto é, há uma disputa do mercado entre as multinacionais que detêm o comando do poder político e econômico e entre estas e os atores econômicos nacional, regional e local.

As estratégias entre as empresas (agroindústrias, concorrentes, clientes, fornecedoras, distribuidoras, poder público etc.) constituem elementos-chave para o poder político-econômico das corporações e garantem a elas a flexibilização das ações nas diversas escalas geográficas. Deste modo, as corporações que atuam como agroempresas assumem a forma de um complexo territorial em rede. O capitalismo globalizado sem os condicionamentos técnicos no território pode "morrer antes mesmo de chegar à praia", porque, atualmente, as técnicas tornaram-se verdadeiros vetores regulacionistas do território e da economia de mercado. Para Santos (1996), as técnicas em si mesmas também são normas, pelo fato de que as técnicas atuais são solidárias: quando uma se impõe, cria-se a necessidade de trazer outras, sem as quais aquela não funciona com eficácia.

$\mathrm{Na}$ agricultura de precisão, por exemplo, as colheitadeiras "inteligentes" não funcionariam com tanta eficácia sem a técnica do GPS, ao mesmo tempo em que este não teria validade nenhuma sem o meio técnico da informação ou, mais especificamente, da internet e, muito menos, sem os satélites de comunicação. Em síntese, cada técnica propõe uma maneira particular de comportamento, envolve suas próprias regulamentações e, por conseguinte, traz para os lugares novas formas de relacionamento e de regulação. $O$ 
resultado dos condicionamentos técnicos no espaço é a criação de um espaço favorável para o desencadeamento do processo de territorialização das empresas globais nas várias escalas do espaço. Ou seja, a regulação do território pelos condicionamentos técnicos está a serviço das corporações.

\section{AÇÕES E TERRITORIALIZAÇÃO DO AGRONEGÓCIO GLOBAL NA MICRORREGIÃO DE RONDONÓPOLIS - MT}

Atualmente, as grandes corporações procuram novas formas de concorrência e coordenação política, fusão e integração de diversas empresas para construir o processo de territorialização e buscar a competitividade. É assim que as empresas globais do agronegócio procuram se territorializar na Microrregião de Rondonópolis-MT. Elas são as principais empresas que atuam no ramo de comercialização/exportação da soja no sudeste mato-grossense. Entre elas destacam-se: Ceval, Archer Daniel Midlands (ADM), Cargill, Bunge e Sementes Maggi Ltda., em Rondonópolis; Coinbra, em Primavera do Leste; Caramuru, em Alto Garças; e ABC, em Pedra Preta. Dentre elas, Ceval, ADM e Sementes Maggi realizam o processamento e a transformação da soja, principalmente a trituração para obtenção de farelo e óleo bruto. As agroindústrias de esmagamento de soja e produção de farelo se articulam também com várias outras, destacando-se as de produção de alimentos e de rações animais e, ainda, as indústrias supridoras de insumos.

As empresas globais do agronegócio atuam em segmentos produtivos em cadeia para facilitar o exercício de sua territorialidade. Estes segmentos, como os da indústria nas cadeias de grãos-farelo-ração e carnes, do comércio e de serviços expressam os segmentos mais diretamente ligados ao complexo agroindustrial que, por sua vez, está diretamente ligado a um conjunto infraestrutural e institucional com os órgãos estatais e as redes técnicas territoriais. A integração é feita no sentido de buscar o fechamento do mercado a favor das empresas globais por meio da reestruturação econômica e industrial no mercado. Silva (2005) afirma que a ADM, a partir dos anos 2000, iniciou uma reestruturação na produção industrial de acordo com o padrão de funcionamento praticado nos Estados Unidos, pela aplicação tecnológica na produção, compreendendo a automação e novos equipamentos de trabalho. Este processo de reestruturação direta ou indiretamente ampliou a sua arena geopolítica no mercado mato-grossense.

O resultado do processo de reestruturação econômica do mercado pode conduzir o desencadeamento do monopólio comercial. Este se faz presente no setor industrial na microrregião, seja no segmento de sementes e nas agroindústrias de esmagamento e processamento da soja, seja no segmento de industrialização como no de comercialização 
da carne. Para exemplificar este raciocínio, temos a suspeita de formação de cartel dos proprietários de frigoríficos atuando com práticas comerciais desleais. Uma reportagem do jornal A Tribuna realizada por Assiz (2005) veiculou informações de que havia a suspeita de formação de cartel dos proprietários de frigoríficos na região de Rondonópolis. Diante deste fato, os pecuaristas denunciaram a prática de cartel dos frigoríficos que teriam aumentado autoritariamente a tabela de classificação de abate de bovino de $15 \%$ para $16 \%$ no boi, de $11 \%$ para $12 \%$ na vaca e imposto a classificação do boi inteiro de menos de 16 arrobas como vaca, com uma redução em torno de $18 \%$ no valor pago pelo frigorífico ao criador. Isso significa dizer que, quando os empresários do agronegócio não conseguem a competitividade pela inovação da técnica nem pelo jogo político-comercial, utilizam-se da corrupção.

Da mesma forma, acontece com as empresas globais do agronegócio que cercam o processo produtivo da soja por todos os lados, ora vendendo insumos, ora comprando/financiando a produção, deixando poucas alternativas para os produtores pequenos e médios. No sentido de poder programar essa política de subjugação aos produtores, a maioria das grandes empresas proporciona empréstimos para o custeio das safras, os quais se tornam verdadeiros "pré-financiamentos" e podem assumir a forma de compra antecipada da produção. Segundo depoimentos de produtores da região, o tratamento dado a eles é diferenciado conforme a empresa, mas, no geral, observa-se o seguinte modelo: seleção dos produtores aptos a receber financiamento; exigência de garantias como a hipoteca da propriedade, dois avalistas, penhor da safra, etc., como afirma Santos (2002). Ou seja, as agroindústrias e as multinacionais ligadas à produção e comercialização de sementes e grãos se articulam dentro do mercado, de forma que os prejuízos e riscos sejam mínimos e, sobretudo, possam manipular o mercado.

Por outro lado, vê-se grande competição entre as poderosas indústrias de insumos agropecuários que atuam na região. Em sua maioria, elas são representadas por empresas multinacionais de grande porte, com enorme capacidade de comercialização, o que torna acirrada a disputa pelo mercado regional. Têm-se também as indústrias de maquinaria, em que há um forte monopólio de empresas no que se refere a tratores e colheitadeiras, fornecidos quase que exclusivamente por Case, John Deere, Massey Ferguson e New Holland, que usam de várias estratégias para conquistar o produtor, como palestras científicas, Dia de Campo, feiras e exposições tecnológicas etc. Dão assistência ao produtor para manter o vínculo, que se desdobra em uma relação assimétrica. Para manter a competitividade, essas empresas geram novas estratégias de comercialização. Como exemplo, as empresas podem vender semente com desconto para o produtor que comprar um pacote de seus produtos (pacote tecnológico) e cria uma relação de favor, de "gentileza". 
Este procedimento comercial caracteriza a venda, enquanto, ao mesmo tempo, há uma obrigação de compra.

A compra antecipada da produção de soja pelas agroindústrias, como forma de financiamento da produção, constitui uma das formas de integração do capital industrial com os produtores de soja, com o objetivo de manter e incrementar a expansão capitalista neste circuito espacial de produção. Este tipo de relação exemplifica como a agroindústria passou a ter o domínio do campo. Vale também lembrar que o monopólio da produção agrícola não acontece apenas com a soja, mas com outros produtos que vão aparecendo no cenário agrário, desde que sejam de interesse do mercado internacional.

Vários agentes econômicos que praticam estas estratégias estão presentes na região. Gupo André Maggi, Ceval, Incomind, Sperafico e ADM possuem, ao todo, mais de seis unidades esmagadoras de soja no estado. A presença desses grupos transnacionais em Mato Grosso não se dá pelo acaso. O monopólio do mercado internacional da soja provoca uma concentração da industrialização e comercialização dos produtos das tradings multinacionais localizadas nos Estados nação. No Brasil, a concentração desta atividade econômica se apresenta apenas em três grupos multinacionais, Bunge, Cargill e ADM, que comercializaram $60 \%$ da safra de 2000 . Desse modo, o mercado da soja é um oligopólio, com poucos compradores, o que deixa os produtores com pequena capacidade de barganha na arena geopolítica comercial. Como é o caso do grupo André Maggi, que compra a matéria-prima do produtor e depois a estoca. Sem recursos para a lavoura, o agricultor recorre às tradings e se submete ao controle financeiro delas (SILVA, 2003).

Outro exemplo da territorialização das empresas do agronegócio ocorre no mercado de sementes de soja, que se estruturou em dois níveis: o primeiro nível diz respeito à comercialização dos materiais genéticos, realizada entre as empresas que trabalham com a pesquisa (empresas de melhoramento genético oficiais e privadas, como Embrapa, Fundação Mato Grosso, Monsoy, Dupont etc.) e as empresas multiplicadoras (ou sementeiros, que multiplicam estes materiais, ou seja, realizam a produção de sementes); o segundo nível refere-se às vendas feitas pelos sementeiros para os produtores de soja, milho e algodão, grãos que têm sua produção destinada à indústria. Os materiais desenvolvidos em parceria no programa Embrapa/Fundação Mato Grosso detêm cerca de $70 \%$ da área plantada; contudo, com a separação das duas empresas, que passaram a ser concorrentes nesse mercado, a Fundação Mato Grosso manteve uma participação de cerca de $80 \%$ desse percentual e a Embrapa de cerca de 20\%, na década de 2000.

Uma das razões que levaram a Fundação Mato Grosso ao final da parceria com a Embrapa foi o envolvimento desta com a multinacional ianque Monsanto, e outra foi que a Monsanto exigia da Embrapa o rompimento do contrato com a Fundação Mato Grosso. A 
Monsanto traça a sua geopolítica no sentido de controlar a questão de sementes no Brasil, mesmo que os produtores da região questionem. A construção desta geopolítica da empresa Monsanto pode partir de duas formas - por uma vertente das verticalidades que é justamente o domínio geopolítico do pacote tecnológico que é imposto aos produtores e as horizontalidades que são desencadeadas de duas formas, uma é que a Monsanto procura difundir as suas tecnologias (sementes transgênicas) territorialmente e aumentar a dependência dos produtores e agricultores e a outra é justamente a resistência dos produtores contra as práticas de monopolização da Monsanto.

A resistência dos agricultores geralmente é operacionalizada pelos sindicatos rurais através de ações processuais na justiça para o não pagamento de royalties de forma abusiva. A principal estratégia da Monsanto para fazer o licenciamento e a cobrança pelo direito do uso da propriedade intelectual industrial é a luta para o fortalecimento e universalização dos aparatos jurídicos de proteção da propriedade intelectual, com vistas a garantir direitos patentários sobre os novos produtos gerados pelos processos biotecnológicos. A criação de um quadro regulatório internacional da produção e comércio de produtos biotecnológicos que visa o direito sobre as patentes constitui-se uma estratégia imposta pelas empresas e organismos internacionais para domínio geopolítico e comercial dos materiais genéticos.

Contudo, esse esforço das grandes empresas manterem o controle geopolítico e o monopólio tem sido dificultado com o aumento da informalidade nesse mercado, isto é, as sementes também podem ser pirateadas. Isto evidencia que, embora as empresas tentem fechar e monopolizar o mercado, sempre haverá uma brecha ou uma reação de outros sujeitos sociais, principalmente daqueles que têm sua pujança política limitada ao nível local e que são coagidos. Uma dessas brechas é a informalidade ou a pirataria no processo de melhoramento genético de sementes, que vem aumentando. Isso fica mais claro com a reportagem do jornal $A$ Tribuna feita por Araújo (2004) relatando que a venda de sementes ilegais movimentou US\$ 685 milhões. A área plantada com sementes ilegais nas culturas de soja, milho, algodão, arroz e trigo aumentou $65,3 \%$ na safra $2003 / 04$. Estes dados incluem sementes multiplicadas ilegalmente, transgênicas e contrabandeadas. A área ocupada com sementes piratas nessas culturas passou de 7,65 milhões de hectares (ou 20\% da área ocupada por essas culturas) em 2002/03 para 12,64 milhões (30\% da área total plantada no período) na safra de 2003/04. Em receita, as indústrias de sementes alegam que deixaram de ganhar US\$ 685 milhões em 2003/4 devido às sementes pirateadas.

Esse aumento de 65,3\% em apenas um ano da pirataria de sementes representa as contrarracionalidades ou as "racionalidades da ilegalidade" ou da informalidade, que estão aumentando cada vez mais, em resposta à imposição autoritária de uma racionalidade superior que se baseia na efetiva implantação imperativa do consumo e das estratégias da 
economia de mercado. É uma cultura unilateral, isto é, que não aceita críticas e muito menos o contrário. Este caráter unilateral e tirânico da atual sociedade capitalista, que se abastece numa cultura artificializada estabelecida de cima para baixo, acaba deparando com fortes resistências em virtude de seu elevado teor de exclusão social. Nem sempre a racionalidade do mundo capitalista consegue apagar as "racionalidades da ilegalidade" ou da informalidade, afirma Milton Santos em sua obra Por uma outra globalização (2000). Vale ressaltar que esta informalidade é fruto de uma situação dialética e contraditória, da própria racionalidade da legalidade.

Outra vertente do processo de territorialização das empresas do agronegócio na região é estimulada pelas políticas territoriais que se estabelecem como condicionamento de uma nova territorialidade, a partir da formação de infraestrutura de transportes hidroviário e rodoviário. No modal rodoviário, segundo Oliveira (1991), o Banco Mundial direcionou sua política de financiamento, por meio do Polonoroeste, para construção e pavimentação da BR-364 (Cuiabá - Porto Velho) e investimentos nas áreas cortadas por essa rodovia, com o objetivo de fomentar programas de colonização em Rondônia e de "regularização fundiária" em Mato Grosso. Em acréscimo a isso, o Banco Mundial se dispôs também a financiar projetos de transporte hidroviário nos canais fluviais do Araguaia e do Tocantins, com o objetivo de dar respaldo ao escoamento da produção de grãos no cerrado do Centro-Oeste. Segundo reportagem do jornal $A$ Tribuna realizada por Oliveira (2004), o ministro dos transportes Alfredo Nascimento propôs liberar $\mathrm{R} \$ 43$ milhões para obras de pavimentação e recuperação de rodovias no Mato Grosso, principalmente para as BR 364, 163 e 174.

No modal hidroviário, temos o trecho dos rios Araguaia e Tocantins que se estende da cidade de Conceição do Araguaia (PA) até a cidade de Tucuruí (PA), com 750 quilômetros de extensão. Estes rios correm sobre rochas cristalinas pré-cambrianas e apresentam muitas corredeiras. A ideia da hidrovia Araguaia-Tocantins é tornar este trecho plenamente navegável para a exportação de grãos do Centro-Oeste aos mercados mundiais constituídos por países como Tailândia, Coréia do Sul, Bélgica, Portugal, Taiwan, Indonésia, Noruega, Holanda, China, Alemanha, Irã e Japão, a preços baixos, aproveitando a navegação fluvial. Em Mato Grosso, temos a hidrovia do rio das Mortes que faz ligação com o rio Araguaia nas imediações de São Félix do Araguaia. A hidrovia do Tocantins, pertencente ao corredor Centro-Norte, se divide em dois trechos. O primeiro, de Peixe-TO a Marabá-PA, com 1.021 quilômetros de extensão, e o segundo, de Marabá - PA à foz do Tocantins, com 494 quilômetros.

O objetivo do projeto de construção da hidrovia é o de transformar esses rios em um corredor de transporte de grãos, minerais e madeira para os portos marítimos do norte do país, sobretudo em São Luiz - MA. Em contrapartida, a lógica empresarial se afasta do 
espaço concreto das populações ribeirinhas e dos povos indígenas que ocupam as margens dos rios Araguaia, Tocantins e das Mortes. É necessário admitir-se que o projeto de perenização da navegação anuncia uma série de problemas ambientais, que são, na verdade, conflitos socioambientais já em curso. As suspeitas de fraude no Estudo de Impactos Ambientais e no Relatório de Impactos sobre o Meio Ambiental (EIA/RIMA) e a oposição de intelectuais, ambientalistas, nações indígenas e camponeses, entre outros, apontam para a aceleração do desmatamento, alteração da qualidade da biótica regional e demais impactos. Os interesses de um segmento social capitalista homogeneizador resultam na oposição de grupos sociais que se sentem marginalizados, bem como no debate em torno da destruição da biodiversidade do cerrado e, com esse condicionamento, surgem conflitos de territorialidade.

A construção desta obra acarreta impactos socioambientais na região do cerrado. Isso está acontecendo, inclusive, graças às políticas de investimento do Banco Mundial. A construção de um corredor intermodal, fazendo conexão com a Estrada de Ferro de Carajás e o porto maranhense de Itaqui, por meio de um ramal ferroviário na altura de Xambioá, favorece mais ainda a logística de escoamento da produção de grãos. Os custos estimados são de US\$222,4 milhões. De qualquer forma, será necessário também a construção do porto de transposição em Barra do Garças - MT, onde os grãos serão retirados dos caminhões, estocados e transportados em balsas para a viagem fluvial (MOTA, 2001). Economicamente, a Microrregião de Rondonópolis será beneficiada com a instalação desta obra para o escoamento de sua produção. Aliás, o município de Rondonópolis foi beneficiado diretamente por meio da construção de 200 quilômetros da ferrovia Ferronorte, a partir de Alto Araguaia, com recursos e financiamento do BNDES e do FINAM (Fundo de Investimento da Amazônia).

Essas políticas de desenvolvimento regional acarretam uma ambiência de concentração da produção agropecuária e de renda. As grandes empresas desterritorializam os sujeitos sociais locais e se territorializam nos lugares. Mudam a estrutura do emprego e de outras relações econômicas, sociais, culturais e morais dentro de cada lugar, afetando igualmente o orçamento público, tanto na receita como na despesa. As empresas aparecem como salvadoras - "trazem desenvolvimento". O poder público, nas várias esferas, fica subordinado às multinacionais e então começa a prevalecer as políticas delas. É assim também, que se alteram as relações sociais dentro de cada comunidade e localidade.

Santos e Silveira (2001) afirmam que com o avanço do processo de fusões as lógicas ditas globais ampliam e aprofundam sua força, e o processo de adoção dessas lógicas planetárias impõe uma coordenação geopolítica do território a favor das empresas globais. Assim, participam das lógicas nacionais e se beneficiam dessa participação no mercado interno, porque têm a tecnologia, a política e a ideologia a seu favor. 


\section{AÇÕES DAS EMPRESAS GLOBAIS DO AGRONEGÓCIO A MONTANTE E A JUSANTE NA MICRORREGIÃO DE RONDONOPOLIS-MT}

Uma forma de analisar o estágio de desenvolvimento das regiões com intensa mecanização pode ser partir da investigação da estrutura do agronegócio, que se compõe pelo complexo agroindustrial (CAI). O sistema agroindustrial se desenvolve de forma articulada e integrada em todo o contexto da produção agropecuária. Para Bellato (1986), o desenvolvimento do agronegócio é promovido pela sua intensa capacidade de integração entre os vários agentes, e, em alguns momentos, pela subordinação destes agentes aos processos de integração e aos contratos de produção. Existem duas formas básicas de integração: a horizontal e a vertical. Para o autor, a integração horizontal é a união ou a associação de duas ou mais unidades de produção na mesma hierarquia, constituída sob controle de uma única empresa ou associação de produtores. Para a integração vertical, entende-se a união de estágios ou setores produtivos em hierarquias diferentes no mercado sob o controle, também, de uma única empresa ou conglomerado. A integração vertical acontece também quando o processamento é feito em único estabelecimento ou as etapas de produção e industrialização são realizadas por uma só empresa, agregando valor ao produto, que é valorizado na primeira oferta após a etapa de industrialização, criando com isso melhores oportunidades de mercado.

O CAl é composto por três segmentos: indústria a montante, agricultura e indústria a jusante. A indústria a montante é a fornecedora de bens de capital e insumos para a agricultura e a indústria a jusante é a processadora de matéria-prima agrícola, denominada de agroindústria. O CAI que se constituiu devido à modernização da agricultura acelerou o processo de subordinação da agricultura ao capital industrial e financeiro. A partir desse processo é que se deu a "industrialização da agricultura". A formação do complexo agroindustrial envolveu a internalização da indústria de máquinas, equipamentos e insumos e a expansão do sistema agroindustrial viabilizada pelas políticas estatais.

O setor a jusante do agronegócio é subdividido em duas partes: produção agroindustrial (CAI) e distribuição. As empresas como a ADM e a Bunge, que tem agroindústrias podem agir nas duas pontas do processo produtivo, isto é, atuam tanto à sua montante, fornecendo serviços, insumos, fertilizantes e agrotóxicos, como à sua jusante, transformando a matéria-prima, comprando e comercializando soja, trigo, algodão e outros cultivares. A possibilidade de agir e movimentar suas ações nas duas pontas do processo produtivo transforma as empresas que têm agroindústrias e as empresas globais do agronegócio em verdadeiros sujeitos sociais que monopolizam o comércio local, nacional e 
internacional e se articulam politicamente para se manter no pódio e ter o domínio sobre o mercado. Nessas condições, a agricultura ficaria no meio, sendo explorada pelos dois lados, isto é, nesse caso quem seria explorado de fato, sem sombra de dúvida, seria o produtor, principalmente aquele de pujança político-comercial menor. A Figura 2 ilustra o processo de subordinação da agricultura às empresas globais do agronegócio a montante e a jusante.

Figura 2 - Subordinação da agricultura (produtores) às empresas globais do agronegócio a montante e a jusante do processo produtivo

\begin{tabular}{|l|l|l|l|}
\hline $\begin{array}{l}\text { A montante: } \\
\text { indústrias de } \\
\text { fertilizantes, de } \\
\text { tratores, } \\
\text { colheitadeiras, } \\
\text { agrotóxicos, etc. }\end{array}$ & $\begin{array}{l}\text { Agricultura: os produtores. } \\
\text { Estes são os únicos atores } \\
\text { sociais que são explorados } \\
\text { pelos dois lados, tanto pelas } \\
\text { empresas do agronegócio } \\
\text { global a montante como a }\end{array}$ \\
\hline
\end{tabular}

Organizado pelo autor.

Rondonópolis, após a década de 1980, caminhou no sentido de uma fase de agricultura tradicional para uma fase de economia alimentar industrializada, ao se ampliar a quantidade de empresas ligadas aos setores a montante e a jusante do agronegócio. $\mathrm{Na}$ indústria a montante, temos a John Deere, que consolida o seu crescimento estratégico no Brasil. Iniciou suas operações no país em 1979, quando assumiu participação de $20 \%$ do capital da Schneider Logemann \& Cia (SLC), fábrica de máquinas agrícolas de Horizontina RS. Em 1999, assumiu integralmente o controle da SLC, dando origem a John Deere Brasil. Nas indústrias de maquinaria, há um forte monopólio de empresas no que se refere a tratores e colheitadeiras, fornecidos quase que exclusivamente por Case, John Deere, Massey Ferguson e New Holland. Na indústria de agrotóxicos (chamados pela mídia burguesa de defensivos agrícolas) temos Dow Agrosciences, Novartis Agro (fusão de Ciba e Sandoz), Monsanto, Basf, Agrevo (fusão de Hoechst e Schering), DuPont, Bayer, Uniroyalchemical etc., que procuram monopolizar o mercado de insumos. Estas empresas estão presentes no mercado regional de equipamentos e agrotóxicos (dados colhidos em entrevista com representante das empresas citadas).

O setor a montante foi o primeiro a chegar à região com a instalação de representantes comerciais das empresas fabricantes de equipamentos agrícolas. A tendência deste setor é aumentar cada vez mais a sua participação na região, por meio da implantação da indústria de equipamentos agrícolas como tratores, implementos agrícolas, equipamentos de armazenamento, colheitadeiras e, também, de insumos inorgânicos e fertilizantes. Em Mato Grosso, este setor detém um dos maiores mercados de insumos e de equipamentos agrícolas do país. Segundo reportagem do jornal $A$ Tribuna de Velasko 
(2005), a cidade de Rondonópolis é o maior polo de fertilizantes do interior brasileiro, com cinco fábricas: ADM, Bunge, Adubos Trevo, Fertilizar e Botânica.

A primeira misturadora de fertilizantes a se implantar em Mato Grosso foi a Fertilizar Fertilizantes e Serviços Ltda., que implantou sua unidade em Rondonópolis em 1990. Posteriormente, a empresa começou a produzir fertilizantes simples, mistos e micronutrientes, tendo a capacidade de produção de 60 toneladas/hora. A ADM, no final de junho de 2003, inaugurou mais uma unidade de fertilizantes em Rondonópolis, o que contribuiu para o processo de integração vertical entre o setor agroindustrial e insumos na região. Esta nova fábrica é a que possui a maior capacidade de produção diária, com quatro mil toneladas/dia, e seus produtos podem atender várias culturas agrícolas em Mato Grosso. Outro gigante com fábrica de fertilizantes em Rondonópolis, a Bunge, tem capacidade diária de ensaque de três mil toneladas, com fabricação de fertilizantes das marcas lap, Manah Serrana e Ouro Verde. Esta empresa contribuiu de forma mais ampla para o processo de integração vertical na região. A empresa iniciou suas atividades na cidade em setembro de 2001. Outra empresa, ainda, que tem uma unidade industrial local atuando no setor é a Botânica Fertilizantes Ltda., que começou a operar na cidade em setembro de 1998. Os principais produtos da unidade são fertilizantes para tratamento de sementes e fertilizantes foliares.

A região, até o final dos anos 1990, já possuía vários empreendimentos a jusante do agronegócio. Entre as agroindústrias de processamento da soja na cidade de Rondonópolis, temos a ADM e a Bunge. A Bunge produz óleo degomado (óleo bruto sem ser hidratado; o óleo hidratado fica mais fino, mais claro, mas para isso passa por um processo de melhoramento). A Bunge veio para Rondonópolis em 1990 e, nos anos 2000, a empresa completou 52 unidades de armazenagem (silos) no Mato Grosso e duas fábricas: uma em Rondonópolis e outra em Cuiabá.

Um total de $99 \%$ da produção industrial local da Bunge é exportada para o mercado internacional. Cerca de $20 \%$ de sua produção industrial é de óleo e $80 \%$ de farelo, que é utilizado para ração animal (aves, suínos etc.). Sua produção é exportada para a Europa e Ásia. As rotas de escoamento são pelo Paraná, pelo porto de Paranaguá e pelo Araguaia. Em entrevista da unidade industrial local, o gerente afirmou que a empresa financia os produtores para fazer o plantio, mas exigem muitas garantias. Entretanto, o gerente não disse quais são elas. Essa exigência constitui uma das formas de manter o domínio econômico e político no processo de territorialização. Na verdade, a Bunge, quando financia os produtores, usa uma estratégia de integração através da agricultura sob contrato, ampliando ainda mais a sua geopolítica comercial regional. As concorrentes mais fortes da 
Bunge são ADM, Cargill e Coinbra (dados colhidos na unidade industrial local em junho de 2005).

A ADM comprou a parte de grãos da Sadia de algumas localidades do estado de Mato Grosso, inclusive a de Rondonópolis. O óleo é patente da Sadia, mas quem produz é a ADM. Com sede em Decatur, Illinois, nos Estados Unidos, esta empresa é considerada líder no processamento de soja, milho, algodão, trigo e canola no país sede. Atua no processamento de sementes oleaginosas, na moagem de grãos, no processamento de cacau (em que é líder mundial), nos setores de bioprodutos, especialidades proteicas, saúde e nutrição humana e animal, na fabricação de produtos à base de amendoim, na comercialização de cereais e no transporte de alimentos. A empresa está presente em 71 países, com 270 fábricas, e está dividida nas áreas de fertilizantes, grãos, indústria, transportes/portos e cacau. Ela é uma das maiores exportadoras de soja do Brasil, país em que tem 10 fábricas. A ADM implantou uma maneira de pensar e fazer agricultura no Brasil por meio da prestação de serviços ao produtor, oferecendo um pacote de serviços a montante e a jusante, que inclui a fabricação de fertilizantes. Isso faz com que sua hegemonia no agronegócio seja cada vez mais fortalecida, contribuindo para o seu processo de territorialização nas várias escalas espaciais do país.

Em janeiro de 2003, a ADM anunciou que havia duplicado a capacidade de produção da fábrica de Rondonópolis e que, a partir de janeiro de 2004, passaria a produzir dois milhões de toneladas de soja ao ano, com perspectivas de processar quatro milhões de toneladas. O farelo, rico em proteínas, é comercializado no mercado interno e externo, sendo utilizado na fabricação de ração animal. Já o óleo refinado é destinado ao mercado nacional e comercializado com quatro marcas: Sadia, Concórdia, Corcovado e Rezende. Em 2001 começou a operação da linha pet (vasilhame de plástico transparente para envasamento do óleo para o consumo final) na fábrica de Rondonópolis, com uma capacidade de envasar 25 mil garrafas/hora.

Além de atuar nas duas pontas do processo, isto é, tanto a montante como a jusante, as empresas do agronegócio procuram estabelecer uma estrutura de logística que lhes possibilite criar seu próprio território e domínio político-comercial no processo produtivo. No caso da ADM, ela dispõe de uma sofisticada infraestrutura de logística, que utiliza os três modais de transporte - rodoviário, ferroviário e fluvial - para o transporte de soja e seus derivados, trigo, milho e açúcar. Para transportar seus produtos no interior do Brasil, a ADM carrega cerca de três mil caminhões por dia e utiliza boa parte do transporte ferroviário nacional disponível, sendo, portanto, uma das maiores usuárias dos serviços da Companhia Vale do Rio Doce e da Ferronorte/Brasil Ferrovias (dados colhidos junto à empresa, por meio da assessoria de informação, com a secretária da empresa ADM em 2005). 
A territorialização do agronegócio global no processo produtivo integrado que se efetiva pelo meio técnico-científico permite às empresas aumentarem a mais-valia por intermédio da agregação de valor ao produto final, pois uma única empresa consegue acoplar várias atividades econômicas num mesmo processo produtivo. O caso do valor agregado no complexo também constitui uma das formas mais capitalistas em uma economia de mercado. Na suinocultura, avicultura, piscicultura e pecuária, a mais-valia é extraída de forma multiplicada por várias vezes do seu valor. Aí, sim, as empresas que atuam a jusante e a montante constroem seu território e sua própria espacialidade - um espaço recheado de contradições sociais e de concentração de renda. Além de ampliar as contradições sociais, amplia-se também a subordinação dos pequenos e médios produtores ao agronegócio, ou seja, as empresas de fertilizantes, insumos, máquinas e defensivos agrícolas vendem estes produtos para os produtores, o que, na verdade, se constitui em um pacote tecnológico geopolítico e comercial de subordinação dos produtores de arena política e comercial menor ao agronegócio.

\section{CONSIDERAÇÕES FINAIS}

As ações e o processo de territorialização das empresas do agronegócio global na Microrregião de Rondonópolis-MT dão-se por meio de articulação e geoestratégias políticas. Para isso, elas dispõem e instrumentalizam o conhecimento técnico-científico, a ideologia da prosperidade baseada na economia de mercado e, sobretudo, a política a seu favor. Essas ações fazem parte de um sistema que atua em conjunto nas várias instâncias do poder político-comercial e jurídico, o que Ihes atribui maior eficácia na execução de seus objetivos. O processo de territorialização destas empresas caracteriza-se por uma ação social racional com objetivos definidos, pela qual se cria um "arranjo territorial" com vistas à busca da certeza de se ter as respostas predefinidas. Mas também é necessária a existência de infraestrutura rodoviária, industrial, energética e a criação de vias intermodais para a garantia de eficiência em suas ações no território.

O processo de desregulamentação/reestruturação faz parte de um processo maior, que é o projeto de modernização que, ao mesmo tempo, conduz ao processo de dominação geopolítica do mercado global e apropriação mercantil da natureza através da ciência e da técnica. Verifica-se também que a tendência atual é universalizar a produção econômica do capital, criando um espaço global sob a lógica globalização/fragmentação, fazendo com que o processo de inclusão/exclusão e ordem/desordem torne-se mais acentuado no território.

Para desencadear o processo de territorialização do agronegócio global na Microrregião de Rondonópolis, a Embrapa, a Fundação Mato Grosso e outras instituições de 
pesquisas científicas se apossam do conhecimento técnico-científico como instrumento para execução deste processo. O arranjo territorial do agronegócio global na região de Rondonópolis é construído por meio dos vetores técnico-científicos e pela dimensão políticoinstitucional, tais como as políticas públicas federais, estaduais e municipais. Neste contexto, o espaço regional é historicamente construído, constituindo-se como um sistema territorial que estabelece conexões diversas no tempo e no espaço, aniquilando fronteiras pré-estabelecidas para a construção de novos arranjos que legitimam as novas relações de poder.

O processo produtivo integrado da cadeia grãos-farelo-ração-carnes que se resume no complexo agroindustrial conduz ao projeto de modernização da atividade econômica agropecuária. Dentro da arena geopolítica global do agronegócio, o processo produtivo integrado e em cadeia cria as condições reais para o processo de territorialização do agronegócio global. A consolidação do processo de territorialização do agronegócio se dá quando as empresas globais costuram um "arranjo territorial" do processo produtivo através da criação de uma logística de manipulação do mercado em suas várias escalas. A dominação total da lógica capitalista (produção, circulação, distribuição e consumo) materializa-se a partir do controle nas duas pontas do processo produtivo do agronegócio - o setor a montante e a jusante -, colocando a agropecuária entre estes setores, totalmente subordinada à logística e as geoestratégias da racionalidade capitalista.

Quando apropriados pelo agronegócio global, os vetores técnico-científicos condicionam uma posição hierárquica dos lugares, desenhando um espaço de centroperiferia desigual. As políticas de desenvolvimento regional, juntamente com os vetores técnico-científicos, construíram na Microrregião de Rondonópolis um espaço hierarquizado, em que se estabeleceu um polo de crescimento. Ao mesmo tempo, criou-se também uma divisão territorial do trabalho capitalista em várias escalas. Na região, percebe-se que há os espaços da divisão técnica e social do trabalho. Nos municípios que adotam a agricultura de precisão, o mercado de trabalho passa por uma qualificação técnica, enquanto outros municípios vizinhos continuam com uma agropecuária tradicional baseada em uma mão de obra menos qualificada.

Quando o poder econômico está associado ao poder político, há o fortalecimento de uma classe empresarial na região e a ascensão desta classe ao comando político do estado (ou do poder público municipal) contribui para fortalecê-la, possibilitando-lhe exercer decisiva influência política. Em pouco mais de duas décadas em Rondonópolis, esta aliança contribuiu com três governadores, dos quais dois são grandes produtores de grãos: Rogério Salles e Blairo Maggi. 


\section{REFERÊNCIAS}

ABRÃO, J. A. Análise dos principais elementos teórico-metodológicos utilizados por Geografia do sudoeste do Paraná. 2012. 175 f. Dissertação (Mestrado em Geografia) Universidade Estadual do Oeste do Paraná, Francisco Beltrão, 2012.

ARAÚJO, V. M. Venda de sementes ilegais, provoca prejuízos ao agronegócio. A Tribuna, Rondonópolis, MT, p. A6, 12 dez. 2004.

ASSIZ, M. R. Formação de cartel de proprietários de frigoríficos na região de RondonópolisMT. A Tribuna, Rondonópolis, MT, p. A7, 19 mar. 2005.

BELLATO, D. A subordinação do camponês no interior das cadeias alimentares: integração e contratos de produção. Contexto e Educação, ljuí, v.1, n. 1/3, p. 93-112, 1986.

CASTILHO, D. Modernização territorial e redes técnicas em Goiás. 2014. 224 f. Tese (Doutorado em Geografia) - Universidade Federal de Goiás, Goiânia, 2014.

CASTRO, I. E. de. O problema da escala. In: CASTRO, I. E. de; GOMES, P. C. C.; LOBATO, R. C. (org.). Geografia: conceito e temas. Rio de Janeiro: Bertrand Brasil, 1995. p. 117-140.

MENDONÇA, M. R. F. de. Modo capitalista de produção e agricultura: a construção do conceito de agronegócio. 2013. 217 f. Tese (Doutorado em Geografia) - Faculdade de Filosofia, Letras e Ciências Humanas da Universidade de São Paulo, São Paulo, 2013.

MONTEIRO, J. L. G. Mudanças espaciais induzidas pelo progresso técnico: a realidade da agricultura mato-grossense. 2004. 283 f. Tese (Doutorado em Geografia) - Universidade Federal do Rio de Janeiro, Rio de Janeiro, 2004.

MOREIRA, R. Formação do espaço agrário brasileiro. São Paulo: Brasiliense, 1991.

MOTA, J. A. O valor da natureza-economia e política dos recursos naturais. Rio de Janeiro: Garamond, 2001.

OLIVEIRA, A. U. Integrar para não entregar: políticas públicas e Amazônia. Campinas: Papirus, 1991.

OLIVEIRA, O. G. Ministro dos transportes propõe mais recursos para obras de pavimentação e recuperação de rodovias em Mato Grosso. A Tribuna, Rondonópolis, p. A5, 15 jun. 2004.

SANTOS, J. W. M. C. Clima e produtividade da soja nas terras de cerrado do Sudeste de Mato Grosso. 2002. Tese (Doutorado em Geografia Física) - Faculdade de Filosofia, Letras e Ciências Humanas da Universidade de São Paulo, São Paulo, 2002.

SANTOS, M. Espaço dividido: os dois circuitos da economia urbana dos países subdesenvolvidos. São Paulo: EDUSP, 2008.

SANTOS, M. Natureza do espaço: razão e emoção. São Paulo: Hucitec, 1996.

SANTOS, M. Por uma outra globalização: do pensamento único à consciência universal. Rio de Janeiro: Record, 2000.

SANTOS, M.; SILVEIRA, M. L. O Brasil: território e sociedade no início do século XXI. Rio de Janeiro: Record, 2001.

SANTOS, R. de S. A microrregião geográfica de Rondonópolis-MT e sua polarização na economia regional. Revista NERA, Presidente Prudente, Ano 19, n. 33, p. 155-180, set. dez. 2016.

SILVA, C. A. F. da. Grupo André Maggi: corporação e rede em áreas de fronteira. Cuiabá: Entrelinhas, 2003. 
O Processo de Territorialização do Agronegócio Global na Microrregião Geográfica de...

SILVA, E. da. Elementos para uma análise do espaço do complexo agroindustrial de Mato Grosso. In: PEREIRA, A. J.; SILVA, E. da; SANTOS, R. de S. (org.). Geografia de Mato Grosso no limiar do século XXI. Rondonópolis: União, 2005.

VELASKO, J. de L. O município de Rondonópolis-MT desponta como grande região do agronegócio no interior do país. A Tribuna, Rondonópolis, p. A7, 22 jan. 2005.

Recebido: setembro de 2018.

Aceito: janeiro de 2019. 